\title{
Fictional Names and Fictional Concepts: A Moderate Fictionalist Account
}

\author{
Eleonora Orlando*
}

Received: 3 March 2020 / Revised: 20 July 2020 / Accepted: 10 November 2020

\begin{abstract}
The main thesis I want to defend in this essay is that a fictional name refers to an individual concept, understood as a mental file that stores information, in the form of different descriptive concepts, about a purported individual. Given there is no material particular a fictional name could be referring to, it will be construed as referring to the concept of a particular, with which many descriptive concepts are associated, in the context of the set of thoughts constitutive of a fictional narrative. A fictional narrative will be thus characterised as a conceptual world, namely, a set of sentence-types semantically correlated with a set of thought-types.
\end{abstract}

Keywords: Fictional name; fictional narrative; fictionalism; fictive, parafictive and metafictive uses; mental file; singular thought.

\section{Introduction}

The main thesis I want to defend in this essay is that a fictional name, like 'Funes' in the following sentence of Borges' short story "Funes the Memorious",

* University of Buenos Aires

(D) https://orcid.org/0000-0002-0153-6558

Bulnes 642 - CP: 1176 Autonomous City of Buenos Aires, Argentina.

$\triangle$ eleonoraorlando@sadaf.org.ar

(C) The Author. Journal compilation (c) The Editorial Board, Organon F.

This article is distributed under the terms of the Creative Commons Attribution-NonCommercial 4.0 International Public License (CC BY-NC 4.0). 
(1) We, at a stroke, perceive three cups lying on a table; Funes would see all the shoots and clusters and fruit comprised by a vine, ${ }^{1}$

refers to an individual concept, understood as a mental file that stores information, in the form of different descriptive concepts, about a purported individual. Given there is no material particular a fictional name could be referring to, it can be construed as referring to the concept of a particular, with which different descriptive concepts are associated, in the context of the set of thoughts constitutive of a fictional narrative. A fictional narrative will be thus characterised as a conceptual world, namely, a set of sentencetypes semantically correlated with a set of thought-types. It is important to point out that the analysis will be thus restricted to purely linguistic fictional narratives, among which the most prominent and interesting ones are literary artworks.

Uses of sentences like (1) are what have been called 'fictive', namely, uses of the very sentences constitutive of "Funes the Memorious", both in the original act, performed by Borges, of creating the fictional narrative and in the subsequent acts, performed by him and many other people, of reading, reciting, memorising or replicating it in some way. But, as is known, there are other kinds of uses of sentences containing fictional names. On the one hand, in parafictives uses, they are intuitively taken to convey the fictional story facts from an external perspective, as exemplified by an utterance of

(2) Funes recovers consciousness with the skill of remembering everything, ${ }^{2}$

during a lecture on Latin-American literature. These uses can be considered to be reports of a fictional narrative's content by means of different words.

1 This is a translation of the original Spanish sentence: "Nosotros, de un vistazo, percibimos tres copas en una mesa; Funes, todos los vástagos y racimos y frutos que comprende una parra." Below, I will make a brief comment on translation.

2 Adapted from: "'Funes the Memoriou' tells the vicissitudes of Ireneo Funes, a peasant from Fray Bentos, who after falling off a horse and hitting his head hard, recovers consciousness with the incredible skill - or perhaps curse of remembering absolutely everything." (https://www.scientificamerican.com/article/borges-andmemory-encounters-with-human-brain-excerpt/) 
On the other hand, there are also the metafictive uses, in which fictional sentences are intuitively construed as alluding to facts that are not part of the fictional story, like the use of

(3) Funes manifests Borges' obsession with the infinite,

in writing a literary essay. Both parafictive and metafictive uses usually target sentences that are not part of what I have called 'the conceptual world of the fiction'. So, in accounting for them, it will be necessary to examine how that world is related to sentences outside its domain. ${ }^{3}$

A clarification point is in order. The core of the proposal may seem not to do justice to the phenomenology associated with the use of fictional discourse: it may be objected that in producing and consuming fiction, in particular, in fictively using sentences with fictional names, we have the impression of referring not to individual concepts but to flesh and blood people. Although I will not be concerned with the phenomenological aspects of our interaction with fiction, I would like to point out that (i) the impression at stake is under-described, since it is mingled with the element of pretence that is characteristic of fictive uses: in fact, in making those uses, we merely pretend to be referring to flesh and blood people, while being perfectly aware that this is not the case; (ii) be that as it may, the metaphysical nature ascribed to an object of reference does not rule out any particular phenomenology associated with an act of reference because no competent speaker can be assumed to have, qua competent speaker, knowledge of the metaphysics of reference. Accordingly, in using sentences containing standard general terms, a competent speaker may be thought to be holding de re attitudes towards substances whose underlying nature she most certainly ignores; likewise, in fictive uses, a competent speaker can be thought to be holding de re attitudes towards objects, in particular, the individual concepts allegedly referred to by fictional names, whose metaphysical nature she may ignore as well. Finally, the peculiarly declarative illocutionary force that will be ascribed to the production of sentences like (1) can also be taken to play a role in pointing to the existence of an

3 Bonomi (2008) introduces a similar distinction between textual, paratextual and metatextual uses. See also (García-Carpintero 2015, 2020, forthcoming). 
"intuitively felt" difference between our dealings with standard and fictional discourse. $^{4}$

The structure of the paper is the following one. In section 2 I will expand on the framework of mental file theory that is being used in the proposal. In section $3 \mathrm{I}$ will try to show how it can be put to work to account for fictive uses. Then, in section $4 \mathrm{I}$ will suggest how an explanation of parafictive and metafictive uses could be developed along similar lines. The last section is a conclusion, in which the fictionalist character of the proposal is brought to the fore.

\section{On mental files}

Thoughts (in particular, propositional attitudes) can be classified into singular and general ones. This classification is related to their contents, since singular thoughts are thoughts about particulars, while general thoughts are quantificational and hence purely descriptive ones. ${ }^{5}$ Likewise, the concepts they involve can be also classified into two main groups: particular concepts, such as individual and indexical ones, ${ }^{6}$ and general concepts, like classificatory and qualitative ones. In terms of an example, the singular thought BORGES IS A WRITER, is constituted, on the one hand, by an individual concept for Borges, what can be called 'the BORGES file', and, on the other, by the descriptive concept WRITER, which can be considered to be stored in that file, together with other ones. ${ }^{7}$ By deploying mental files a person is able to entertain singular thoughts. This capacity is thus naturally associated with the ability to use sentences containing genuinely referential expressions, like proper names and indexicals. Files have

4 I thank an anonymous referee for pressing me to add this clarification.

5 As is known, thoughts can also be classified in relation not to their contents but to their types; i.e., into beliefs, desires, doubts, predictions, etc.-according to the Representational Theory of the Mind, they can be distributed in different 'boxes'. See, for instance, (Fodor 1990).

${ }_{6} \quad$ Some philosophers think that there are also particular concepts corresponding to the referential use of definite descriptions. See, for instance, (Recanati 2009).

7 As is fairly common, I use capital letters to designate thoughts and concepts. 
been taken to be the mental counterparts of genuinely singular terms. ${ }^{8}$ In a nutshell, files have been put to work in defence of Singularism and against Descriptivism, namely, the general view that both thought and language have devices for singular reference.

Getting more specific, mental files are a new way of conceiving of particular concepts. A mental file is a mental representation (metaphysically, a mental particular) that stores information (and misinformation) concerning an individual under a certain label, which can be updated on the occasion of each new encounter with the individual at stake (Crimmins and Perry 1989, Crimmins 1992, Perry 2001, Jeshion 2009 and 2010, Korta and Perry 2011, Friend 2011, Recanati 2012, Salis 2013). Mental files are relationally, as opposed to satisfactionally, individuated: in a paradigmatic case, whereas a descriptive concept selects an individual by virtue of the fact that it satisfies a certain description (satisfactionally), a mental file does it by virtue of the fact that it is directly related to it (relationally). The kinds of relations between a mental file and the corresponding individual include perception, memory, testimony, and the historical chains of communication underlying the use of proper names: though being different kinds of relations, they are usually referred to by means of the global term 'acquaintance'. So, the two main features of a mental file are (i) its aptitude for bundling information and misinformation, and (ii) the ascription of the bundled information and misinformation to a particular individual.

As mentioned before, 'acquaintance' is thought to encompass different kinds of relations, among which historical chains of communication can be considered to play a major role. The reason for that is that they allow for a close relationship between names and concepts: many individual concepts originate when the corresponding names are introduced in a public language, and they can be transmitted, along with names, across different times and communities. Now, as is known, historical chains of communication do not require a direct epistemic relation like perception to get off the

8 Moreover, files have been thought to play a key role in accounting for differences in cognitive significance between co-referential terms, which does not necessarily involve considering them to be playing a semantic function in relation to singular terms (i.e., to be an aspect of their meaning). I defended this option, a version of a two-level semantics, though, in (Orlando 2017). 
ground. According to Kripke (1980)'s seminal work, the mechanism of reference fixing can be: (i) purely causal, (ii) mixed, that is, causal-descriptive, or (iii) purely descriptive. In the first case, there is a causal relation to an object underlying an act of perception, by virtue of which the name gets grounded on the object in question, which gives rise to a naming practice. The second case is exemplified by Kripke with the different baptisms of Venus: in one of them, 'Hesperus' is bestowed on the planet by means of a causal relation underlying an act of perception and the simultaneous use of a description, 'the evening star' (or something equivalent to it), that was thought to select it even if in fact it did not, since Venus is not a star; at any rate, reference fixing descriptions do not have to be true of the object they are used to pick out as the referent of the accompanying name. As for the third case, it is exemplified by Kripke with the baptism of Neptune: what anchors 'Neptune' in Neptune is exclusively a description, entertained by Le Verrier, along the lines of 'the planet that causes perturbations in Uranus' orbit'.

Moreover, closer to the present topic of concern, there are also cases in which not only is there no perceptual link at the baptism but also no object whatsoever to be perceived (or, for that matter, described). Kripke (2011, 2013) encompasses the possibility of a historical chain of communication to get started even when there is nothing whatsoever being named or talked about in the case of the introduction of fictional names by the creators of fiction. He claims that authors, when introducing names for their fictional characters, are merely pretending to name real people, while there is nobody they could be related to. Even if, afterwards, at a later stage, those fictional characters start playing the role of (abstract) referents, at an early stage, pretence gives rise to an empty naming practice. Likewise, Donnellan (1974) considers instances of historical chains ending up in what he calls a 'block', namely, certain events that preclude a referent from being identified, such as hallucinations, mistakes or cases of non-uniqueness. Along these same lines, Sainsbury (2005) claims that a baptism can be successful in originating a naming practice even if it fails to introduce an object: those are cases where there is reference (namely, an expression with a referential function is involved) without a referent. Devitt and Sterelny (1987) and Devitt (1996) seem to be endorsing a similar claim: in their framework, the singular 
content involved in those uses is constituted by the causal networks themselves, which are taken to play the role of external senses. Therefore, the thesis that the competent use of proper names in natural language is one of the main sources of mental files should lead one to acknowledge the existence of files that are grounded on no object whatsoever.

These considerations prompt a restatement of the initial characterisation: a mental file is a mental representation that, in the paradigmatic cases, stores information (and misinformation) concerning a particular individual under a certain label. The two main features mentioned at the beginning of this essay still hold modulo that important modification: a mental file (i) bundles information (and misinformation) (ii) to a purported particular individual. Accordingly, a singular thought is a thought entertained as a consequence of taking some information flow to come directly from an alleged individual, namely, even if the object at stake does not exist. In a nutshell, thinking singularly involves an object-directed but not necessarily an objectinvolving mental activity. ${ }^{9}$

\section{Fictive uses}

\subsection{Fictional names: their introduction}

(or their reference fixing mechanism)

In most cases, or at least, in the most interesting ones, fictional names are introduced as part of the process of creating a fictional narrative, which, also in the most interesting cases, constitutes a literary artwork. ${ }^{10}$ It may

$9 \quad$ As argued in (Orlando 2017), this should lead us to give up any kind of strong conception of acquaintance, according to which being acquainted with an object requires either having a direct epistemic relation to an object or belonging in a communication chain whose first member has a non-descriptive epistemic relation to an object. As is known, mental file theorists are divided among those allowing for such a strong interpretation of acquaintance (Evans 1982, Salmon 1986) and those opposing it (Perry 2001, Jeshion 2009, 2010, Friend 2011, Recanati 2012, Salis 2013).

10 Searle (1975) claims that fictional narratives cannot be identified with literary artworks because there are fictional narratives that are not considered to be part of literature (a comic strip, for instance) and, vice versa, there are literary artworks 
be thought, fairly uncontroversially, that a fictional narrative is an abstract entity of some sort; more specifically, but still without intending to go deep into metaphysical issues, I propose to construe it in terms of what I've called a 'conceptual world', namely, a set of pairs of sentence-types and thoughttypes, grounded on the tokens entertained by the author during the creation process. ${ }^{11}$ On this assumption, a fictional narrative involves the creation of a prima facie peculiar kind of abstract object - since, as is known, abstract objects are usually thought to be atemporal/eternal and as such they cannot be created. Even if this belongs in a set of well-known problems (such as the creation, disappearance and our epistemic relation to abstract objects) that are beyond the scope of this essay, they might be at least partially handled by appealing to the role of exemplars. In terms of Goodman (1968)'s classification of artworks into the allographic and autographic ones, literature belongs in the former group, which means that it allows for multiple instances, or exemplars, of the fiction in play. An author creates a fictional narrative by creating a particular exemplar of it: by semantically correlating, at a time and place, a certain set of sentence-types with a certain set of thought-types, grounded on her own thought-tokens. ${ }^{12}$ The initial

that are not fictional (Truman Capote's In Cold Blood, Thucydides' historical narratives). Two clarifications may be relevant to this point. First, as pointed out in the introduction, the present analysis is restricted to purely linguistic fictional narratives - hence, those including a visual component, like comic strips and movies, are excluded. Secondly, although I will not be concerned with the difference between literature, journalism and history and there might well be cases that belong in the intersection of these fields, paradigmatic literary artworks, as opposed to paradigmatic journalist articles and historical works, are not factual, or based on alleged facts, but fictional narratives.

11 This turns out to be more complicated than it may seem at first sight, since the conceptual world of a fictional narrative can be thought to include not only the thought-types literally expressed by the corresponding sentence-types but also other thoughts that are tightly related to them (either conversationally implicated by them or derived from them in some other way). I will ignore this complication in what follows. I thank Manuel García-Carpintero for a comment that prompts the addition of this footnote.

12 From now on, I will use the feminine pronoun for the author and the masculine pronoun for the reader. 
literary exemplar is the first set of sentence-tokens of those types that gets semantically correlated with the author's (set of) thought-types; literary exemplars might thus be construed as semantic vehicles of thought-types. In as far as my main topic, fictional names, is concerned, a certain nametype gets semantically correlated with a certain fictional file-type, which thereby becomes its referent. ${ }^{13}$ In what follows, I will try to justify this central claim.

According to the considerations put forward in the previous section, it is plausible to think that when an author introduces a fictional name, she will open a mental file for a fictional character, even if there is no material object she is related to. Notice that, in as far the fictional file is going to be tokened many times throughout the creation of the narrative, the different tokens give rise to a certain type of file. Now, whereas in introducing scientific names like 'Vulcano', and even mythological ones like 'Zeus', the speaker can be ascribed a referential intention that is directed towards a supposedly material object, this is not the case with fictional names: the author who introduces a fictional name knows there is not, and could not be (except for a spectacular coincidence) a corresponding material object. ${ }^{14}$

13 Strictly speaking, at a baptism it is not a name-type but an articulation-type (for instance, /Olivia/) that gets correlated with a particular (in the paradigmatic case, Olivia), since names are individuated in terms of their meanings, of which their referents are at least a part. So, the name-type 'Olivia' is the set of tokens referring to the same Olivia. Another Olivia has another name-type. I avoid this complication for the sake of simplicity.

14 What about the inclusion in fictional narratives of names associated with real people, as the trite example of 'Napoleon' in Tosltoy's War and Peace? There are two main positions concerning this issue: non-exceptionalism and exceptionalism. According to the former, paradigmatically represented by Kripke (2013) and Friend (2000, 2011), those names are standard names that are imported into the fiction. The latter position, defended by García-Carpintero (2015, 2020 and forthcoming), claims that those names are not imported ones but are as fictional as 'Anna Karenina': they do not refer to real people but concern characters that are similar, in some respects, to real people. I support exceptionalism, since I take all names occurring in fictional narratives to refer to individual concepts, and, as it will be clear below, in most of their uses, they are part of either what I have called 'the conceptual world of the fiction' or an equally conceptual interpretative extension of it. 
Accordingly, it is possible to think that her referential intention is directed towards her own creation, the file opened in association with the character's name and functioning as an anchorage for the information and misinformation concerning that character.

This may be understood along the lines of the well-known Fregean Thesis of Reference-Shift depending on the kind of sentential context involved. As is known, according to Frege, if a word occurs within quotation marks, it does not refer to its usual referent but to itself:

If words are used in the ordinary way, what one intends to speak of is their reference. It can also happen, however, that one wishes to talk about the words themselves or their sense. This happens, for instance, when the words of another are quoted. One's own words then first designate words of the other speaker, and only the latter have their usual reference. We then have signs of signs. In writing, the words are in this case enclosed in quotation marks. Accordingly, a word standing between quotation marks must no be taken as having its ordinary reference. (Frege 1892, 58-9)

Moreover, if a word occurs under the scope of a psychological verb, in a socalled 'context of indirect speech', it does not refer to its usual referent either but to its customary sense. Quotation marks and psychological verbs are then indicative of the presence of a referential shift; words and senses are the possible entities reference might shift to. As is clear from Frege's account, they are both independently motivated kinds of entities: words are taken to exist all along, and positing senses is independently justified on account of the problem of the difference in cognitive significance between pairs of sentences containing different but co-referential terms - namely, the so-called 'Frege's Puzzle'.

My point is that positing mental files is also justified on independent reasons: the ontological commitment to mental files is motivated, as mentioned in the previous section, by the defence of Singularism against Descriptivism. Consequently, it can be considered that when there is no possible outward referential intention, there is a referential shift from the material world to the realm of thought. More specifically, since in creating a fictional narrative the author is definitely not concerned with the material world (at least, not primarily concerned with it), it may be thought that 
the fictional names she introduces do not refer, as usual, to material individuals, but unusually to the mental files she opens for her characters, namely, to fictional individual concepts. Using a fictional name involves deploying a fictional file, namely, tracking not a material object but a concept. Falling short of any syntactic indicating device like quotation marks or psychological verbs, the author's referential intentions can be brought to the fore. ${ }^{15}$ Notice, though, that the Fregean Thesis of Reference-Shift is general enough not to necessarily involve some other Fregean theses, in particular, the thesis that what is referred to in non-standard sentential contexts might be a meaning component in standard ones, namely, a sense. Accordingly, fictive statements need not be construed as introducing an intensional, i.e., non-extensional, context.

The proposed reference-shift may get further support from the intuitive, and widely acknowledged, fact that in uttering a sentence like (1) the author does not have an assertive intention, namely, the intention to present a content as a candidate for being true or truth-assessable. As also Frege $(1892,1918)$ initially pointed out, fictive uses are not performed with the purpose of making assertions and hence cannot have a truth-value. ${ }^{16}$ Their function is not manifesting an aspect of the Truth but producing an aesthetic effect - which can be more clearly appreciated if we take into account, as before emphasised, that the introduction of fictional names should be viewed as part and parcel of the creation of a fictional narrative. Along these lines, many fictionalists, paradigmatically represented by Walton (1990), have suggested that fictive uses can be only fictionally true, namely,

15 As pointed out by Simpson (1964, 113-4), Frege does not provide us with a general criterion to recognise the kinds of sentential contexts that can motivate a reference-shift.

16 "In hearing an epic poem, for instance, apart from the euphony of the language we are interested only in the sense of the sentences and the images and feelings thereby aroused. The question of truth would cause us to abandon aesthetic delight for an attitude of scientific investigation. Hence it is a matter of no concern to us whether the name 'Odysseus', for instance, has reference, so long as we accept the poem as a work of art." (Frege 1892, 63) This could be construed as another argument put forward by Frege to the effect that fictive statements are neither true nor false - the other one being jointly based on the lack of reference of fictional names and the Principle of Compositionality. 
they can be considered true only in the framework of a pretence or "a game of make-believe". Along the same lines, they have claimed that their use involves no referential intention at all - and that they are to be thus analysed, or paraphrased away, in terms of descriptive sentences. The alternative I am trying to suggest is that there is still a referential intention in play but its target has shifted: it is directed towards not the usual material object but an individual concept that originated in the process of creating a fictional narrative. It is a sui generis referential intention. As is known, referring is not a speech act on a par with, for instance, asserting, ordering or promising, since it can be presupposed by the performance of any kind of speech act.

Moreover, the fact that the author can be taken to be involved in a pretence or a game of make-believe may be considered to be also indicative of the fact that her referential intention is not what it should be and she may try to appear it to be, namely, an intention directed towards a material individual. This would be only what the author pretends to be doing. But then what she is in fact doing is something rather different: she has the intention to refer to the character - according to the present proposal, the individual concept - she has concocted, together with the story. ${ }^{17}$

There are two features that I would like to emphasise. First, the author's performance is different from the common speaker's introduction of a standard proper name, since it is an aspect of the complex process of creating a fictional narrative. Accordingly, introducing a fictional name involves establishing a correlation between a name-type and a file-type that will end up being part of a fixed system of correlations between sentence-types involving that name and thought-types involving the corresponding file. What is introduced is not a detached name for an isolated individual, as when a real person is baptised 'Olivia', but a name for a fictional character, namely, a "piece" of a certain narrative structure, playing a specific role in the whole it belongs to. (This will help explaining why any ensuing use of that name will be linked to the creation of the fictional narrative.)

17 As is clear, the pretence is completely explicit, and the reader agrees to play a role in it, as much as it happens to spectators in a theatre. So, both author and reader can easily identify the author's real referential intention underneath the pretension.

Organon F 28 (1) 2021: 107-134 
Secondly, and closely related to the previous observation, this file-type can be taken to gradually incorporate, through the creation process, all and only the features and facts ascribed to the fictional character by the author. In terms of the example, in writing "Funes the Memorious", Borges must have entertained, among others, the following singular thoughts concerning his main character: FUNES WOULD SEE ALL THE SHOOTS AND CLUSTERS AND FRUIT COMPRISED BY A VINE; FUNES KNEW THE SHAPES OF THE SOUTHERN CLOUDS AT DAWN ON APRIL 30, 1882; FUNES COULD COMPARE THEM IN HIS MEMORY WITH THE STREAKS ON A BOOK OF SPANISH COVER THAT HE HAD SEEN ONLY ONCE. Accordingly, Borges can be credited with having loaded his FUNES file with these pieces of information, among others: SEEING ALL THE SHOOTS AND CLUSTERS AND FRUIT COMPRISED BY A VINE; KNOWING THE SHAPES OF THE SOUTHERN CLOUDS AT DAWN ON APRIL 30, 1882; BEING ABLE TO COMPARE THEM IN HIS MEMORY WITH THE STREAKS ON A BOOK OF SPANISH COVER THAT HE HAD SEEN ONLY ONCE. Fictional files, in as far as they play specific roles in the context of a narrative structure, are initially loaded with all and only the information and misinformation that an author decides to store in them during the process of creating that narrative. (Notice that this includes the misinformation conveyed by the author by means of what has been called 'an unreliable narrator', namely, a point of view of the facts constitutive of the story that is not to be trusted for different possible reasons: the narrator is ignorant, confused or mistaken about those facts, she is deceitful, she is an occasional or systematic liar, she has a distorted perception of reality, etc. $)^{18}$

It may be worth including a metasemantic aside. As mentioned in the previous section, a mental file is usually individuated in terms of not the information and misinformation it contains but the particular object it gets related to at a certain moment and place. If there is no object involved, as

18 The narrator may not be part of the story being narrated, as is the case with heterodiegetic narratives, as opposed to homodiegetic narratives in which the narrator is identical to one of the characters. For a comprehensive examination of the relationships between the author, the narrator and the characters in the story, as much as the different levels of a fictional narrative, see (Predelli 2020). 
is the case with a fictional file, the individuation is still not descriptive but historical or based on the file's origin. In terms of the example, what makes the FUNES file the particular file it is is not the information and misinformation that Borges decided to store in it but the fact that it was originally opened by Borges as part of his process of creating "Funes the Memorious". Therefore, its belonging in a certain narrative structure ends up being essential to its identification. But this does not imply that the file identity is given by the list of descriptive concepts that are stored in it, or that reference to the file can be understood in terms of the application of a list of predicates corresponding to those concepts. The proposal does not then collapse into a version of descriptivism concerning the meaning of fictional names.

According to what has been argued so far, when Borges comes up with (1), he uses the name 'Funes' with the intention to refer not to a material object but to the individual concept he has just opened for a character that plays a major role in the narrative structure of "Funes the Memorious". But he is also storing a representation of the property of seeing all the shoots and clusters and fruit comprised by a vine in that character's file. As mentioned before, he can be taken to have entertained the singular thought FUNES WOULD SEE ALL THE SHOOTS AND CLUSTERS AND FRUIT COMPRISED BY A VINE. Accordingly, it is plausible to claim that the above-mentioned reference-shift also affects the predicative part of the sentence: the meaning of the predicate is not the property itself but a representation of that property, namely, a descriptive concept. It is then a global reference-shift. The semantic content of (1) would then be a thought, a purely conceptual content.

Notice that the proposed framework allows thus for a more natural motivation for the distinction between exemplifying and encoding a property, characteristic of different realist accounts (Zalta 1983, Castañeda 1989, Kripke 2013). Fictive uses express not the exemplification but the codification of a property (by a fictional character) because they express not external facts but thoughts.

\subsection{A speech act hypothesis}

Some fictionalists, such as Currie (1990) and García-Carpintero (2007, 2013, 2019), have attributed to fictive uses a dedicated illocutionary force, 
the fiction-making force: according to this view, they are performed with the intention of making the occasional reader imagine to be imagining (or de se imagine) the content expressed by means of his recognition of that very intention. Without intending to get into the details of this position, I would like to suggest that if there is a fiction-making force it seems to me not to be on a par with other ones such as the assertive and the directive but to be a subkind of what Searle classifies as declarative force, namely, the force characteristic of those acts whose illocutionary point is to create something, "cases where one brings a state of affairs into existence by declaring it to exist" (Searle 1969, 358).

As is clear, the declaration in these cases is not explicit, namely, there is no illocutionary-force indicating device, as the verb 'baptise' in the famous "I baptised this ship Queen Elizabeth"; in this sense, they can be compared to cases like "You are fired". The central point is that if the author successfully performs the act of creating a narrative in which certain characters feature in a certain fictional story, then there is such a narrative. An original fictive use is a speech act that plays a constitutive role in the creation of a fictional narrative, what I have called a 'conceptual world'. In terms of the example, if Borges uses (1) as part of successfully creating a fictional narrative, then there is a fictional narrative in which a character who goes by 'Funes' sees all the shoots and clusters and fruit comprised by a vine, namely, "Funes the Memorious". And, getting more specific, in this fictional narrative the character goes around doing different things and, in particular, performing different kinds of speech acts. ${ }^{19}$ One may even think that this kind of declarational act is backed up by an extra-linguistic institution, in a loose sense of the word, in which the author and her audiences occupy a special place, namely, the institution determined by the social practices of producing and "consuming" literature.

More specifically, the kind of speech act involved in an original fictive use, namely, in the fictive use made by the author of a fictional narrative, might be assigned two interrelated illocutionary points, along the lines of

19 When the narrator is not a character of the story (i.e., in heterodiegetic narratives), she still belongs, somehow, in the narrative, and all the different speech acts that she performs in narrating the fictional facts are, somehow, part of the narrative (even if they are not part of the fictional facts or the plot). 
the promulgation of a law by a legislator (as opposed to its application by a judge): "Promulgating a law has both a declarational status (the propositional content becomes law) and a directive status (the law is directive in intent)" (Searle 1969, 368-369). Likewise, an original fictive use has also both a declarational status, its content becomes part of an artwork, and a directive status, since that content has a normative character vis à vis future uses. As will be explored in 3.3, the ensuing fictive uses of (1) can be construed as uses whose content replicates the content of its original use, namely, the one made in the context of creating the corresponding fictional narrative. ${ }^{20}$

\subsection{Fictional names: the transmission of reference (or their reference borrowing mechanism)}

As is known, historical chains of communication have been basically put forward to account for the transmission of reference among the different members of a linguistic community across time and through different linguistic communities. If we stick to Kripke's original proposal and some of its main developments, the mechanism of reference transmission or reference borrowing is mostly causal, which means that it does not require the presence of an epistemic component. Historical chains are not, in most cases, epistemic conveyers of information; they are different in this respect from perception, memory and testimony (namely, the other sources of singular thought mentioned by mental file theorists). Although Kripke explicitly says that he will not provide us with either necessary or sufficient conditions for someone to take part or adequately insert in a historical chain, the suggestion is that having the same referential intention as the person from whom the expression was borrowed is enough.

${ }^{20}$ As is known, declarative force is compatible with different sentence moods, namely, with declarative, imperative and interrogative sentences. Likewise, it is possible to make an assertion by using an interrogative sentence ("Hasn't the government promised not to increase taxes?"), to give an order by using a declarative sentence ("You come back later"), to insult or express contempt for someone by using an imperative sentence ("Move to a separate line, you sudacas!"), etc. 
By performing acts of reading, reciting, memorising or, in general, replicating in some way a fictional narrative, different people (in general, replicators) can access its constitutive conceptual world. ${ }^{21}$ They can be thereby thought to be part of multiple communication chains leading to the creation, by its author, of the conceptual world in question, namely, the moment in which a certain set of sentence-types, by virtue of the above-mentioned kind of referential shift, gets semantically correlated with a set of thoughttypes - and, in particular, in which a certain fictional name gets semantically correlated with a fictional file. In terms of the example, there is a communication chain connecting the reader's use of 'Funes' in understanding (1) with its original introduction as a name for the FUNES type-file (grounded, in turn, on the multiple token-files in Borges' mind).

More specifically, a replicator's insertion in a historical chain of communication involves, in most literary cases, his causal interaction with a particular exemplar of the work at stake, namely, a set of tokens of the sentence-types with which the author's thought-types were semantically correlated at the creation stage. The mediation of the exemplar makes it manifest that a fictional name is not the kind of name that is detachedly used for an isolated individual but one that is used as part of the interaction with a narrative structure in which it plays a certain role - and outside of which it does not make any sense or has a different meaning, as it happens to 'tower', 'bishop', 'pawn', etc. outside a player's interaction with a chess board, in the context of a game. Accordingly, the communication chain is made not just of isolated particular uses but of particular uses that take place in the context of the replicator's interaction with an exemplar. A particular use of a fictional name connects the replicator with its referent, the corresponding file-type, by means of presenting him with a particular instance of that correlation, provided by an exemplar. His referential intention determines his insertion in a communication chain leading to the original file-type.

By interacting with a particular exemplar, a replicator opens his own file for the fictional character, where all the corresponding information and misinformation gets gradually loaded. The individual concept instantiated in his mind is of the same type as the one originally correlated with the

21 This set may comprise the very author at a later stage, once the creation process is over. 
name and of the many instances constitutive of the communication chain leading to it. So, in a sense, the concept is also part of a world external to him - though, not of course, the material world but the conceptual world of a fictional narrative. Fictional conceptual worlds are public, since they are introduced in (more or less institutionalised) social practices of creating and consuming literary artworks, and are shared by all those people who succeed in inserting in communication chains leading to those works. ${ }^{22}$

As before mentioned, fictional conceptual worlds play a normative function in relation to replicating (and also, as explained below, reformulating) processes. Accordingly, the kind of declarative speech act involved in replication seems to be more similar not to the promulgation of a law by a legislator but to its application by a judge: the replicator enforces the narrative as much as a judge' decision enforces an existent legislation, to which she is supposed to be loyal or faithful-her declarative acts, whatever they are, are not free but regimented. Likewise, the declarative acts of a replicator are regimented by the fictional narrative she is replicating. Therefore, it seems more appropriate to classify them in terms not of truth and falsity but of faithfulness and unfaithfulness to the conceptual world of the fictional narrative - as suggested in (Sainsbury 2010). The faithfulness-conditions of a replicative fictive use of (1) are thus specified not in terms of an individual having a certain property (or belonging in a certain set of individuals) but in terms of the descriptive concept SEEING ALL THE SHOOTS AND CLUSTERS AND FRUIT COMPRISED BY A VINE belonging in the FUNES file in the conceptual world of "Funes the Memorious".

Notice, though, that a replicator is free to store not just the adequate information and misinformation flowing from the short story but also, due

22 There is then an aspect in which fictional names may be found more akin to natural kind terms than to standard names. In general in using 'water' the speaker is related to a natural substance by being in touch with an instance of it, namely, a particular sample of water. Likewise, in reading "Funes the Memorious" the reader is related to Borges' fictional narrative (a conceptual world) through an instance, namely, a particular exemplar of the short story. In particular, in understanding 'Funes' the reader is related to the original 'Funes'-FUNES correlation through (grasping) a particular instance of it, i.e., the 'Funes'-FUNES correlation offered, and prompted, by the corresponding exemplar.

Organon F 28 (1) 2021: 107-134 
to distractions or misunderstandings, some inadequate misinformation. The presence of some descriptive concepts in a certain fictional name file is then comparable to the presence of BORN IN SWITZERLAND and AUTHOR OF 100 YEARS OF SOLITUDE in the BORGES file. The inclusion of concepts that are different from the ones originally ascribed by the author is an issue that is closely related to the distinction between different kinds of uses of fictional sentences, which will be the focus of the next section.

\section{Parafictive and metafictive uses}

As mentioned in the introduction, fictional names can also appear in sentences that are used not in acts of creating or replicating the original narrative but in acts of reformulating it, the so-called 'parafictive uses', as exemplified by the use of (2), repeated below,

(2) Funes recovers consciousness with the skill of remembering everything,

in giving a lecture on Latin-American literature. This sentence is not included in the set of sentence-types constitutive of the conceptual world of "Funes the Memorious" but its use is meant to report on an aspect of the fictional story - in particular, what happens to its protagonist - with words that are different from the ones chosen by the author. In the previous terms, it involves storing the concept RECOVERING CONSCIOUSNESS WITH THE SKILL OF REMEMBERING EVERYTHING in the FUNES file. Consequently, the case provides us with an example of a kind of information that can be stored in a fictional file, which does not flow directly from its original source but is the product of an interpretative process (however superficial it might be).

Anyway, a reformulator's referential intention seems to be directed towards the corresponding file, so that the occurrence of 'Funes' in (2) can be taken to refer to the FUNES file, and its predicate, to express the same character's aspect expressed by different predicates occurring in the conceptual world of the short story, namely, it can be taken to be semantically equivalent to a subset of them (like SEEING ALL THE SHOOTS AND CLUSTERS AND FRUIT COMPRISED BY A VINE). In other terms, 
parafictive uses also involve a global reference-shift: the reformulator is talking about not the material world but a conceptual world that may be considered an interpretative extension of the fictional narrative. Accordingly, the semantic content of (2) is also a thought, namely, something constituted by a file and a descriptive concept and, hence, purely conceptual.

An act of reformulating a fragment of a fictional narrative could also be considered a declarative act, akin (not to a legislator's promulgation of a new law but) to a judge's application of a standing law. But it metaphorically alludes to those cases in which the law is not directly applied but involves a previous process of interpretation. Moreover, it may also be taken to provide us with an example of a mixed force or double illocutionary point, this time of what Searle has called 'representative declarations'. In his own words:

Both the judge and the umpire make factual claims: "You are out", "You are guilty". Such claims are clearly assessable in the dimension of word-world fit. Was he really tagged off base? Did he really commit the crime? They are assessable in the word-toworld dimension. But at the same time both have the force of declarations. If the umpire calls you out (and is upheld on appeal), then for baseball purposes you are out regardless of the facts in the case, and if the judge declares you guilty (on appeal), then for legal purposes you are guilty. (Searle 1969, 360)

Likewise, there is a sense in which a parafictive use can be assessed with respect to its relation to the world: it can be considered true or false depending on its accordance or discordance with the pre-existent narrative (representative force); but there is also a sense in which it involves the creation of an interpretative extension of that narrative (declarative force). Accordingly, the parafictive interpretation of (2) comes out true because it accords with the fictional facts originally included in Borges' short story, but it also gives rise to the creation of an equally conceptual extension of it. $^{23}$

23 Notice that the corresponding sincerity condition is (what may be called) a parafictive belief: in the example, the belief that there is a fictional narrative, "Funes the Memorious", in which Funes recovers consciousness with the skill of remembering 
In a nutshell, on its parafictive interpretation, a sentence containing a fictional name can be semantically correlated with a thought that does not belong in the conceptual world of a fictional narrative but determines an interpretative extension of it - common to all the people exercising the capacity to reformulate the corresponding narrative in different words. If that thought is equivalent to a subset of the thought-types constitutive of the original conceptual world, it can be taken to be true, namely, to accord with the original fictional story.

Without intending to go deep into the topic, I would say that translation is a form of reformulation: translated sentences are not part of the conceptual world of a fictional narrative. So, again, the translation of an original sentence (what (1) in fact amounts to, as specified in footnote 1) involves an act of reformulating the narrative - and it should be thus considered on a par with parafictive uses.

Moreover, as made explicit in the introduction to this essay, the interpretative task encompasses further uses: acts of critically analysing a fictional narrative, such as the use of the above-mentioned (3), repeated below,

(3) Funes manifests Borges' obsession with the infinite,

also not a constitutive part of the conceptual world of "Funes the Memorious". A use of this sentence is meant to provide us with an analysis of the character, in this case, its relation to Borges' characteristic topics, namely, time, labyrinths, the universe, maps, books, libraries, repetition, circles, all of them alluding to infinity. It ascribes the character a feature that is certainly not stored in his file in the conceptual world of the short story.

Now, in this use, on the one hand, the speaker's referential intention can also be taken to be directed towards the FUNES file; accordingly, the occurrence of 'Funes' in (3) can be said to refer to the FUNES file. However, on the other hand, the predicate neither expresses a descriptive concept chosen by Borges nor can it be considered to be semantically equivalent to a subset of them but expresses a property that alludes to the fictional narrative in which the character belongs - more specifically, it expresses a property that the short story shares with other narratives by the same author.

everything or the belief that, according to "Funes the Memorious", Funes recovers consciousness with the skill of remembering everything. 
The property at stake is thus a literary property, the kind of properties that are ascribed to fictional characters by virtue of the critical reflection that is characteristic of literary theory and criticism. Accordingly, the semantic content of (3) is not a pure thought or purely conceptual, since it involves a combination of something conceptual, the FUNES file, and something not conceptual, the property of manifesting Borges' obsession with the infinite. The reference-shift only affects the fictional name but not the predicate; as opposed to the previous cases, it is a partial reference-shift.

Although a certain component of simulation is involved, the act of critically analysing a character seems to lead to genuine assertions, as it is intuitively the case. Accordingly, on its metafictive interpretation, (3) may come out as true or false depending on whether the property of manifesting Borges' obsession with the infinite can be ascribed to the FUNES file in the framework of a literary informed analysis of the short story-hence, independently of both the conceptual world of "Funes the Memorious" and any interpretative extension of it.

Now, as is clear, a literary property might be correlated with a literary descriptive concept, which could be also stored in a character's file. This case provides us with still a further example of a kind of information, stored in a file, which does not flow directly from its original source but is the product of an interpretative process - this time, not a superficial one but one requiring some literary competence or some literary informed reflection on the corresponding fictional narrative.

Summarising, as a consequence of the different possible kinds of uses, a fictional file can store three kinds of descriptive concepts:

(i) fictive uses involve descriptive concepts belonging in the conceptual world of the fictional narrative (SEEING ALL THE SHOOTS AND CLUSTERS AND FRUIT COMPRISED BY A VINE);

(ii) parafictive uses involve descriptive concepts belonging in an interpretative extension of that world (RECOVERING CONSCIOUSNESS WITH THE SKILL OF REMEMBERING EVERYTHING);

(iii) metafictive uses involve literary properties but those properties can be associated with literary descriptive concepts (MANIFESTING BORGES' OBSESSION WITH THE INFINITE). 
Accordingly, when a reader utters (1) he is replicating the author's ascription of a descriptive concept to an individual concept in the context of the creation of a fictional narrative; when he utters (2) he is reformulating the author's original ascription of a descriptive concept to an individual concept, in accordance with the facts originally narrated; when he utters (3) he is asserting that a certain individual concept has a certain literary property but he can be taken to also be storing the corresponding literary concept in the respective fictional file. Notice that, in a certain way, these literary concepts can be considered to be second-order ones, since they are theoretical (literary theory) concepts about fictional concepts. $^{24}$

\section{Conclusion: Moderate Fictionalism}

As is known, the different accounts of fictional names can be classified into two main groups: realist, and anti-realist or fictionalist. According to realist positions, fictional names refer to fictional entities, namely, entities with a peculiar metaphysical status; among them, there is Neo-Meinongianism, for which fictional entities are concrete but nonexistent (Parsons 1980, 1982); Possibilism, for which they are existent but merely possible (Lewis 1978); and Abstractism, for which they are actual but abstract (Kripke 1973, 2013, Thomasson 1999, Salmon 1978, 2002, Predelli 2002, Voltolini 2006). Without going into the details of each variety, realist positions have a theoretical advantage and disadvantage in common. Their main advantage consists in their conception of fictional names as being mostly devices for singular reference, which considerably simplifies the syntactic analysis of the fictional sentences containing them. As for the disadvantage, they increase the ontological commitment, by introducing some sui generis entities, to a level that, if possible, should be avoided. So, fictionalist positions have aimed at avoiding esoteric ontologies and claimed

24 The fact that a fictional file can store different kinds of descriptive concepts has inspired the claim that two different kinds of files can be associated with a certain fictional name, as in so-called 'TwoFileness Accounts', such as the one put forward by Terrone (2018). 
that fictional names are empty singular terms, which in turn have committed their defendants to the non sufficiently explanatory gappy propositions, and the consequent need to move the explanation from the semantic to the pragmatic realm (Everett 2000, Taylor 2000, Braun 1993, 2005). Alternatively, they have appealed to complicated paraphrastic analyses, in which fictional names ended up disappearing (Walton 1990, Sainsbury 2005, 2010). So, ontological austerity is not completely free.

The account hereby proposed can be considered to fall within the fictionalist camp. However, it does not take fictional names to be empty singular terms and hence does not make use of gappy propositions. Moreover, it is neither involved with paraphrases, since sentences like (1) are taken to be what they appear to be on face value: singular sentences concerning fictional characters. As must be clear, though, it involves an ontological commitment to individual and descriptive concepts, and to fictional narratives. As explained before, I construe fictional narratives, or fictional conceptual worlds, in terms of sets of pairs of sentence-types and its semantic correlates, namely, thought-types. Fictional names could be thus taken to refer to parts of the abstract objects that are the fictional narratives in which they occur. But notice, first, that the proposal does not involve an ontological commitment to peculiar or sui generis abstract objects that are created simultaneously with fictional narratives (hence, on top of them), as is the case with the cultural artifacts and the unobservables posited by literary theory, with which typical abstractist approaches identify literary characters. Secondly, those narratives' parts are individual concept-types, which in turn need not be conceived as universals but can be construed in terms of relations of resemblance among particulars, i.e., relations among qualitatively similar mental representations tokened both in the author's and the readers' minds (as it would follow from resemblance nominalism and class nominalism). ${ }^{25}$ To emphasise, the only ontological commitment, aside from the commitment to narratives, is the relatively uncontroversial commitment to mental representations partly constitutive of them, which might be in turn conceived of in terms of resembling mental

25 For a defence of resemblance nominalism, see, for instance, (Rodriguez-Pereyra 2002). 
particulars - be that as it may, they are not peculiar or sui generis abstract entities. $^{26}$

Summarising, the main thesis hereby defended is that fictional names refer to individual concept-types, or mental file-types, which are components of the set of thought-types constituting the conceptual world of a fictional narrative. This conceptual world, initially instantiated by the exemplar created by an author, is then transmitted to future communities of readers through their insertion in a historical communication chain, on grounds of their interaction with new exemplars. Readers are replicators: their fictive uses of sentences containing fictional names are associated with singular thoughts that are of the same type as the ones originally entertained by the author. But they can also be reformulators and critics, namely, they can entertain singular thoughts involving an interpretation of the original ones, which are associated, respectively, with their parafictive and metafictives uses of those sentences. Consequently, there are interpretative extensions and critical analysis of fictional narratives, which, as opposed to their original, constitutive conceptual worlds, are not shared by all the readers. Parafictive and metafictive uses give rise to further conceptual worlds, closely related to the original ones, that overlap and crisscross among those members of the linguistic community who get involved with literary issues.

\section{Acknowledgements}

I would like to thank Piotr Stalmaszczyk for inviting me to take part in this issue, an anonymous reviewer for some interesting suggestions, and Manuel GarcíaCarpintero for his insightful comments to a previous version of this essay.

$26 \quad$ As suggested by an anonymous reviewer, I am aware that the difference between the position hereby defended and abstractist theories may be considered not a significant one. That is why I have called it 'moderate' fictionalism. As far as I can see, their respective kinds of ontological commitment are, though, different, as I have tried to make it explicit. 


\section{References}

Bonomi, Andrea. 2008. "Fictional contexts." In Perspectives on Contexts, edited by P. Bouquet, L. Serafini, and R. H. Thomason, 215-50. Stanford: CSLI Publications.

Borges, Jorge Luis. 1944. "Funes el memorioso." In Jorge Luis Borges. Obras Completas 1923-1972 (Ficciones), 485-90. Buenos Aires: Emecé Editores.

Braun, David. 1993. "Empty Names." Noûs 27: 449-69.

Braun, D. 2005. "Empty Names, Fictional Names, Mythical Names." Nô̂s 39: 596-631. https://doi.org/10.2307/2215787

Castañeda, Hector-Neri. 1989. Thinking, Language, and Experience. Minneapolis: University of Minnesota Press.

Crimmins, Mark.1992. Talk about Beliefs. Cambridge: The MIT Press.

Crimmins, Mark, and Perry, John. 1989. "The Prince and the Phone Booth: Reporting Puzzling Beliefs." The Journal of Philosophy 86: 685-711. https://doi.org/10.2307/2027014

Currie, Gregory. 1990. The Nature of Fiction. Cambridge: Cambridge University Press.

Devitt, Michael. 1996. Coming to Our Senses. A Naturalistic Program for Semantic Localism. Cambridge: Cambridge University Press.

Devitt, Michael, \& Sterelny, Kim. 1987. Language and Reality. Cambridge: The MIT Press.

Donnellan, Keith. 1974. "Speaking of Nothing." The Philosophical Review 83: 3-31. Evans, Gareth. 1982. The Varieties of Reference, edited by John McDowell. Oxford: Oxford University Press.

Fodor, Jerry. 1990. A Theory of Content and Other Essays. Cambridge: The MIT Press.

Frege, Gottlob. 1892. "On Sinn and Bedeutung." In The Frege Reader, edited by M. Beaney, 151-71. Oxford: Blackwell.

Frege, Gottlob. 1918. "The Thought: A Logical Inquiry." Mind 65: 289-311.

Everett, Antony. 2000. "Referentialism and Empty Names." In Empty Names, Fiction and the Puzzles of Non-Existence, edited by Antony Everett and Thomas Hofweber, 37-60. Stanford: CSLI Press.

Friend, Stacie. 2000. "Real People in Unreal Contexts." In Empty Names, Fiction and the Puzzles of Non-Existence, edited by Antony Everett and Thomas Hofweber, 183-203. Stanford: CSLI Publications.

Friend, Stacie. 2011. "The Great Beetle Debate: A Study in Imagining with Names." Philosophical Studies 153 (2): 183-211.

https://doi.org/10.1007/s11098-009-9485-4 
García-Carpintero, Manuel. 2007. "Fiction-Making as An Illocutionary Act." Journal of Aesthetics and Art Criticism 65: 203-16. https://doi.org/10.1111/j.1540594X.2007.00250.x

García-Carpintero, M. 2013. "Norms of Fiction-Making." British Journal of Aesthetics 53: 339-57. https://doi.org/10.1093/aesthj/ayt021

García-Carpintero, Manuel. 2015. "Is Fictional Reference Rigid?" Organon F 22 (Supplementary Issue): 145-68.

García-Carpintero, Manuel. 2019. "Normative Fiction-Making and the World of the Fiction." Journal of Aesthetics and Art Criticism 77 (3): 267-79. https://doi.org/10.1111/jaac.12660

García-Carpintero, Manuel. 2020. "Referential Indeterminacy in Fiction." Journal of Applied Logics 7 (2).

García-Carpintero, Manuel. (forthcoming). "Singular Reference in Fictional Discourse." Disputatio.

Goodman, Nelson. 1968. Languages of Art. An Approach to a Theory of Symbols. New York: The Bobbs-Merrill Company Inc.

Jeshion, Robin. 2009. "The Significance of Names." Mind \& Language 24 (4): 370403. https://doi.org/10.1111/j.1468-0017.2009.01367.x

Jeshion, Robin. 2010. "Singular Thought: Acquaintance, Semantic Instrumentalism and Cognitivism." In New Essays on Singular Thought, 105-40. Oxford: Clarendon Press.

Korta, Korta and Perry, John. 2011. Critical Pragmatics. An Inquiry into Reference and Communication. Cambridge: Cambridge University Press.

Kripke, Saul. 1980. Naming and Necessity. Cambridge: Harvard University Press.

Kripke, Saul. 2011. "Vacuous Names and Fictional Entities." In Philosophical Troubles. Collected Papers vol.1, 52-74. Oxford: Oxford University Press.

Kripke, Saul. 2013. Reference and Existence: The John Locke Lectures. Oxford: Oxford University Press. (Based on the John Locke lectures originally delivered in 1973) https://doi.org/10.1093/acprof:oso/9780199928385.001.0001

Lewis, David. 1978. "Truth in Fiction." In Philosophical Papers vol. 1, 261-80. Oxford: Oxford University Press.

Orlando, Eleonora. 2017. "Files for Fiction." Acta Analytica 32: 55-71. https://doi.org/10.1007/s12136-016-0298-8

Parsons, Terence. 1980. Nonexistent Objects. New Haven: Yale University Press.

Parsons, Terence. 1982. "Are There Nonexistent Objects?" American Philosophical Quarterly 19: 365-71.

Perry, John. 2001. Reference and Reflexivity. Stanford: CSLI Publications.

Predelli, Stefano. 2002. "'Holmes' and Holmes: A Millian Analysis of Names from Fiction." Dialectica 56: 261-79. https://doi.org/10.1111/j.1746-

8361.2002.tb00242.x 
Predelli, Stefano. 2020. Fictional Discourse. Oxford: Oxford University Press. https://doi.org/10.1093/oso/9780198854128.001.0001

Recanati, Francois. 2009. "(Anti-)Descriptivism, Mental Files, and the Communication of Singular Thoughts." Manuscrito 32 (1): 7-32.

Recanati, Francois. 2012. Mental Files. Oxford: Oxford University Press.

Rodriguez-Pereyra, Gonzalo. 2002. Resemblance Nominalism. A Solution to the Problem of Universals. Oxford: Clarendon Press.

Sainsbury, Mark. 2005. Reference without Referents. Oxford: Clarendon Press. http://doi.org/10.1093/0199241805.001.0001

Sainsbury, Mark. 2010. Fiction and Fictionalism. London: Routledge.

Salis, Fiora. 2013. "Fictional Names and the Problem of Intersubjective Identification." Dialectica 67 (3): 283-301. https://doi.org/10.1111/1746-8361.12031

Salmon, Nathan. 1986. Frege's Puzzle. Cambridge: The MIT Press.

Salmon, Nathan. 1998. "Nonexistence." Noûs 32: 277-319. https://doi.org/10.1111/0029-4624.00101

Salmon, Nathan. 2002. "Mythical Objects." In Meaning and Truth. Investigations in Philosophical Semantics, edited by J. Campbell, M. O' Rourke and D. Shier, 105-23. New York: Seven Bridges Press.

Searle, John. 1969. "A Taxonomy of Illocutionary Acts." In Language, Mind and Knowledge, edited by K. Gunderson, 344-369. Minneapolis: University of Minnesota Press.

Searle, John. 1975. "The Logical Status of Fictional Discourse." New Literary History 6: 319-32. https://doi.org/10.2307/468422

Simpson, Thomas M. 1964. Formas lógicas, realidad y significado. Buenos Aires: Eudeba.

Taylor, Kenneth. 2000. "Emptiness without Compromise." In Empty Names, Fiction and the Puzzles of Non-Existence, edited by Antony Everett and Thomas Hofweber, 17-36. Stanford: CSLI Publications.

Terrone, Enrico. 2018. "Twofileness. A Functionalist Approach to Fictional Characters and Mental Files." Erkenntnis, https://doi.org/10.1007/s10670-018-0097-2

Thomasson, Amie. 1999. Fiction and Metaphysics. Cambridge: Cambridge University Press. https://doi.org/10.1017/CBO9780511527463

Voltolini, Alberto. 2006. How Ficta Follow Fiction. A Syncretistic Account of Fictional Entities. Dordrecht: Springer. https://doi.org/10.1007/1-4020-5147-6

Walton, Kendall. 1990. Mimesis as Make-Believe: On the Foundations of the Representational Arts. Cambridge: Harvard University Press.

Zalta, Edward. 1983. Abstract Objects. Dordrecht: Reidel. https://doi.org/10.1007/978-94-009-6980-3 